\title{
Improving access to specialist care for adolescent girls with disabilities
}

\section{Grace Pereira, Naomi Gerson-Sofer}

Oxleas NHS Foundation Trust, London, UK

\section{Correspondence to}

Dr Grace Pereira, Oxleas NHS Foundation Trust, Greenwich, London SE18 3RG, UK; grace. pereira@nhs.net

Received 31 October 2017 Revised 2 November 2017 Accepted 7 November 2017

\section{SLinked}

- http://dx.doi.org/10.1136/ jfprhc-2017-101746

CrossMark

To cite: Pereira G, GersonSofer N. BMJ Sex Reprod Health 2018;44:14-15.
Childhood disability affects 4.0\%$7.5 \%{ }^{12}$ of the population, therefore every GP practice, developmental paediatrician and acute paediatrician will at some point in time be expected to advise with respect to the changing needs of this group, particularly in anticipation of puberty and throughout adolescence.

A common example could be a 12-year-old girl with autism and severe intellectual disability, who is sensitive to physical or environmental changes and has limited self-care skills, needing help with toileting, dressing and personal hygiene, who is now approaching puberty. Her parent or carer anticipates the onset of menarche with growing apprehension, and seeks information from their general practitioner (GP) or paediatrician on how to manage this when it occurs, whether it can be postponed, and who can offer advice. Managing menstruation would entail managing the associated hygiene problems, pain, and emotional distress this could cause. Another example could be a 15 -year-old with moderate learning difficulties, who can manage her menstruation but who may be vulnerable to being sexually abused. A third example might be a 16-year-old cognitively able girl who is immobile due to cerebral palsy and who is inquiring about sexual relationships and her ability to bear children.

The parents of such adolescent girls are often very keen for anticipatory advice, which is not easily accessible due to the paucity of trained specialists in this field. Parents will often seek this advice from their GP and local paediatricians, who may not have the necessary training to address the complexities of a normal physiological process in an individual with complex needs.

The accompanying review entitled 'Contraception for adolescents with disabilities: taking control of periods, cycles and conditions ${ }^{3}$ is a breath of fresh air in bringing the needs of these girls into the spotlight, when research on young females with disabilities is so scarce. The article provides a comprehensive review of the physiological, pathological, emotional-behavioural, ethical and legal considerations of young female adolescents with disabilities. It then covers various presentations and needs of the child and family and offers management options. The article also looks at the existing legal framework, including issues around mental capacity and consent, which is fundamental in such cases.

The Greenwich Child and Adolescent Sexual Health Service (known locally as $\mathrm{CASH}$ ) provides a high level of expertise which can be accessed locally, and thus avoids the need for referral to tertiary services. The service offers the flexibility of telephone contact, or review within the special needs school or in a dedicated clinic. Community paediatricians often refer adolescent girls to the CASH service for anticipatory advice prior to menarche, regulating the menstrual cycle and managing associated symptoms, contraceptive advice and promoting safe sex.

With growing demands for this service in children with disabilities, postgraduate training posts focusing on sexual health and contraception in adolescents should be more widely available in the UK. This will aid development of local services to address the unmet needs of this growing cohort of children.

Dr Dickson's review captures the broader spectrum of sexual health needs in young girls with disabilities and provides comprehensive guidance to support clinical decisions.

\section{Competing interests None declared.}

Provenance and peer review Commissioned; internally peer reviewed.

(C) Article author(s) (or their employer(s) unless otherwise stated in the text of the article) 2018. All rights reserved. No commercial use is permitted unless otherwise expressly granted. 


\section{REFERENCES}

1 Blackburn CM, Spencer NJ, Read JM. Prevalence of childhood disability and the characteristics and circumstances of disabled children in the UK: secondary analysis of the Family Resources Survey. BMC Pediatr 2010;10:21.
2 Rosenbaum P. Childhood disability and social policies. BMJ 2009;338:b1020.

3 Dickson J, Thwaites A, Bacon L. Contraception for adolescents with disabilities: taking control of periods, cycles and conditions. J Fam Plann Reprod Health Care 2018;44:7-13.

\section{Monstrous menstrual myths}

A recent news item ${ }^{1}$ has shone a spotlight on what is generally an unmentionable part of life for women globally. Nepal has introduced legislation to criminalise a longstanding local practice whereby a menstruating woman must leave her home, has to sleep wherever she can find a place, such as an agricultural shed, and if of school age, must miss school. What is the basis for such a practice, and is it unique to Nepal?

The development in humankind of monthly ovarian cycles, and therefore recurrent reproductive opportunity, is credited with being the evolutionary launching point for the survival and success of the species. ${ }^{2}$ These remarkable cycles occur for a substantial part of a woman's non-pregnant and non-lactating lifespan, with the only outward physical sign being the menstrual period that ensues if conception has not occurred. For early peoples a flow of blood from a wound was either followed by death, or if fortunate, by complete healing. So this recurrent but non-fatal loss of blood was a puzzling and alarming mystery, and wherever there is mystery or fear, myth and taboo are bound to follow.

In 1978 Shuttle and Redgrove published a groundbreaking book, examining the myths, prejudices and facts surrounding menstruation, "one of the most basic natural processes of human life" . ${ }^{3}$ It is paradoxical that while the root cause of the fear or envy - was women's magical capacity for bringing forth life, the societal taboos that evolved focused almost entirely on the menstrual 'reboot' following non-reproductive cycles. ${ }^{2}$ Beliefs evolved in many separate early communities that a menstruating woman is dangerous to men, beasts or crops. Taboos and rituals that developed included enforced seclusion, prohibitions on activities, often those that included physical contact, and food deprivation. Taboos were generally underpinned by intense negative messages to women of the danger they posed to themselves and others, and any transgression might incur immediate violent death.

Four decades on from Shuttle and Redgrove's book, taboos persist in many cultures, ranging from formalised and explicit, as per recent custom in Nepal, to subtle and inexplicit remnants, which are widespread globally. All are to various degrees disabling to women, since menstrual days comprise nearly a quarter of a woman's calendar days, and are very undermining, particularly to girls on the threshold of adulthood.

All credit then to Nepal for introducing the new legislation. ${ }^{1}$ The penalty for transgression against the new law is a 3-month jail sentence and a US\$30/£23 fine, but as Nepalese activists emphasise, the law on its own will be insufficient - diligent enforcement is crucial, and education campaigns are needed to change community beliefs, a key precursor to changing behaviour. In the meantime, the message this new law sends is invaluable in affirming the dignity and human equality of every woman born.

\section{Pamela Warner}

Associate Editor, BMJ Sexual \& Reproductive Health, and Reader in Medical Statistics, Usher Institute, University of Edinburgh, Edinburgh, UK; p.warner@ed.ac.uk

Provenance and peer review Not commissioned; internally peer reviewed.

\section{References}

1 BBC News. Nepal criminalises banishing menstruating women to huts. 10 August 2017. http://www.bbc.co.uk/news/ world-asia-40885748 [accessed 16 August 2017].

2 Miles R. The women's history of the world. Glasgow, UK: Paladin, 1988.

3 Shuttle P, Redgrove P. The wise wound: the myths, realities, and meanings of menstruation. New York, NY: Grove Press, 1978, 1988. 